\section{Telerheumatology in the era of COVID-19 in. South Africa}

To the Editor: The COVID-19 pandemic around the world has dictated that strict measures such as social distancing need to be implemented in order to avoid transmission of SARS-CoV-2. ${ }^{[1]}$ The world has been forced to adapt to a new normal, which has greatly impacted on economies, social activities and healthcare systems. The measures of social distancing have presented unprecedented challenges that force people and businesses to create new and innovative ways to continue communication and function. Technology has played a vital role in bridging the barrier to close contact that the pandemic has created.

In healthcare, the traditional face-to-face consultation for stable patients or patients who did not need emergency care was either limited or no longer possible during hard lockdowns enforced by governments worldwide, ${ }^{[2]}$ particularly for those usually seen in outpatient departments. Exploration of novel measures to mitigate this gap in the healthcare service delivery led to a rapid rise in research on telemedicine (TM) or telehealth. Several TM tools and programmes have been used during COVID-19 outbreaks worldwide and seen to provide an alternative solution to the challenge of continuing provision of healthcare services to patients during lockdowns while adhering to social distancing guidelines.

Prior to the COVID 19 outbreak, TM research was steadily on the rise, as the capabilities of information and communication technologies have provided new possibilities and alternatives to traditional and fundamental practices in healthcare and patient interaction. The World Health Organization describes TM as 'the delivery of health care services, where distance is a critical factor, by all health care professionals using information and communication technologies for the exchange of valid information for diagnosis, treatment and prevention of injury and disease. It can also be used for research and evaluation, and for the continuing education of health care providers, all in the interests of advancing the health of individuals and their communities. ${ }^{\text {[3] }}$

Most practitioners in this technological era may have already used TM in some form or another, including telephonic communication between colleagues, sending radiological images or results using technological platforms, or communicating with patients using telephone, email or other asynchronous platforms. Technology has allowed capabilities such as remote virtual consultation and examination through the internet and high-definition images on phones and cameras. Other available tools such as email, smartphone applications, and wearable devices with mobile sensors and trackers have resulted in increased expansion of TM's remote diagnostic and monitoring capabilities.

TM research aims to address challenges that countries have experienced in the healthcare sector such as accessibility in both urban and rural areas, cost-effectiveness of services for both the patient and the healthcare provider, and providing good-quality services. ${ }^{[4]}$ Earlier pilot studies mainly looked at these variables and compared them with the traditional face-to-face consultation, and in the past two decades there has been an increase in the utilisation of TM in both primary and subspecialty care, mainly in developed regions such as Europe, China and North America. ${ }^{[5,6]}$

Other areas of research into TM use aimed to prove its costeffectiveness compared with the traditional frameworks that are currently used, but earlier reviews state that they were unable to make such conclusions owing to poor-quality studies and short-term pilots that simply did not have the evidence to prove cost-effectiveness. ${ }^{[6]}$ Although the evidence of cost-effectiveness may not have been proven, the challenge presented by the COVID-19 pandemic has highlighted the limitations of the traditional healthcare system. TM provides a solution that simply aims to provide the means to continue and improve the delivery of healthcare services in situations that may hinder achievement of the same or improved health outcomes through traditional consultation.

During the COVID-19 pandemic, all healthcare departments and services were mobilised into efforts for the care, diagnosis and treatment of COVID-19. Elective services and outpatient departments were closed for most patients who required non-urgent care or who were simply following up for chronic management of their disease. ${ }^{[7]}$ The most affected and neglected areas during the pandemic were the outpatient departments, where services were either discontinued or postponed to later dates.

In disciplines such as rheumatology, where most patients are seen as outpatients, follow-up proved to be very challenging, as much in our facility at Tygerberg Hospital as in most parts of the world. ${ }^{[8]}$ Most rheumatology patients receive immunosuppressive therapy that may put them at risk of infection, necessitating continuous monitoring. ${ }^{[9]}$ During the COVID-19 pandemic these patients found themselves restricted and afraid, without any form of follow-up, and this situation resulted in some being admitted for acute disease flares. ${ }^{[8]}$

It therefore became rheumatology teams' responsibility to identify patients at risk of infection, including SARS-CoV-2 infection, with the aim of shielding them from unnecessary exposure during the pandemic balanced against the risk of a flare and compromise with regard to their underlying condition. ${ }^{[10]}$ We adopted this policy at our rheumatology clinic at Tygerberg Hospital. Once patients were identified, communication needed to be established, and this is where TM has played a role - in the form of a phone call in our setting. The term telerheumatology (TRH) has been coined to describe this feature in rheumatology.

TRH research on implementation and health outcomes is growing but limited, although limited reviews on studies done up to 2018 found that TRH is an effective tool for improving access to rheumatology services, especially in rural areas. A gap identified in TRH was how and when to implement TRH: namely, which rheumatological disease, which phase in the disease, and which form of TRH to use in different scenarios. ${ }^{[11]}$ In order to contribute to such research, we have embarked on a study that will assess the feasibility of TRH in SA. We aim to identify barriers to the implementation of TRH that may exist in the healthcare system, at a patient level as well as at a healthcare provider level, in our setting in a developing country where the majority of citizens receive healthcare services from the public sector.

\section{S D Ntshalintshali}

Division of Rheumatology, Department of Internal Medicine, Tygerberg Hospital and Faculty of Medicine and Health Sciences, Stellenbosch University, Cape Town, South Africa sipho.duncan@gmail.com

\section{T Zwane}

Department of Internal Medicine, Tygerberg Hospital and Faculty of Medicine and Health Sciences, Stellenbosch University, Cape Town, South Africa

\section{R du Toit}

Division of Rheumatology, Department of Internal Medicine, Tygerberg Hospital and Faculty of Medicine and Health Sciences, Stellenbosch University, Cape Town, South Africa 
1. Chu DK, Akl EA, Duda S, Solo K, Yaacoub S, Schünemann HJ. Physical distancing, face masks, and eye protection to prevent person-to-person transmission of SARS-CoV-2 and COVID-19: A systematic review and meta-analysis. Lancet 2020;395(10242):1973-1987. https://doi.org/10.1016/ S0140-6736(20)31142-9

2. Verma $B K$, Verma $M$, Verma VK, et al. Global lockdown: An effective safeguard in responding to the threat of COVID-19. J Eval Clin Pract 2020;26(6):1592-1598. https://doi.org/10.1111/jep.13483 3. World Health Organization Global Observatory for eHealth. Telemedicine: Opportunities and developments in member states: Report on the Second Global Survey on EHealth. WHO, 2010. https:// apps.who.int/iris/handle/10665/44497 (accessed 4 May 2021).

4. Roine R, Ohinmaa A, Hailey D. Assessing telemedicine: A systematic review of the literature. CMA 2001;165(6):765-771

5. Hersh WR, Helfand M, Wallace J, et al. Clinical outcomes resulting from telemedicine interventions: A systematic review. BMC Med Inform Decis Mak 2001;1:5. https://doi.org/10.1186/1472-6947-1-5

6. Iribarren SJ, Cato K, Falzon L, Stone PW. What is the economic evidence for mHealth? A systematic review of economic evaluations of mHealth solutions. PLoS ONE 2017;12(2):e0170581. https://doi. org/10.1371/journal.pone.0170581
7. Lee Y, Kirubarajan A, Patro N, Soon MS, Doumouras AG, Hong D. Impact of hospital lockdown secondary to COVID-19 and past pandemics on surgical practice: A living rapid systematic review. Am J Surg 2020 (epub 11 November 2020). https://doi.org/10.1016/j.amjsurg.2020.11.019

8. Bonfá E, Gossec L, Isenberg DA, Li Z, Raychaudhuri S. How COVID-19 is changing rheumatology clinical practice. Nat Rev Rheumatol 2021;17:11-15. https://doi.org/10.1038/s41584-020-00527-5

9. Widdifield J, Bernatsky S, Paterson JM, et al. Serious infections in a population-based cohort of 86,039 . Widdifield J, Bernatsky S, Paterson JM, et al. Serious infections in a population-based cohort of 86,039
seniors with rheumatoid arthritis. Arthritis Care Res (Hoboken) 2013;65(3):353-361. https://doi. org/10.1002/acr.21812

10. Price E, MacPhie E, Kay L, et al. Identifying rheumatic disease patients at high risk and requiring Price E, MacPhie E, Kay L, et al. Identifying rheumatic disease patients at high risk and requiring
shielding during the COVID-19 pandemic. Clin Med (Lond) 2020;20(3):256-261. https://doi, shielding during the COVID-19

11. McDougall JA, Ferucci ED, Glover J, Fraenkel L. Telerheumatology: A systematic review. Arthritis Care Res (Hoboken). 2017;69(10):1546-1557. https://doi.org/10.1002/acr.23153

S Afr Med J 2021;111(8):695-696. https://doi.org/10.7196/SAMJ.2021.v111i8.15810 